\title{
Reflections on the Teaching of "Tea Culture and Teaware Appreciation" in College Humanistic Quality Course
}

\author{
Bao Chen ${ }^{1, a}$, Sheng $\mathrm{Bi}^{2, \mathrm{~b}}$, and Zhenghao $\mathrm{Qiu}^{3, \mathrm{c}}$ \\ ${ }^{1}$ College of Technology and Art, Jingdezhen Ceramic University, \\ ${ }^{2}$ Jingdezhen Ceramic University Ceramic Art Department, Jingdezhen Jiangxi Province 333403 \\ 5126571@qq.com
}

Keywords: Humanistic quality elective courses; Tea culture; Teaware appreciation courses

\begin{abstract}
Since 2007, many scholars at home and abroad have advocated the application of tea culture to quality education. More Chinese scholars have made practical attempts on the quality education of tea culture. At present, many colleges and universities across the country have established elective courses such as Tea Culture, Chinese Tea Ceremony and Tea Culture and Tea Health. In 2014, our college also set up an elective course on Tea Culture and Ceramic Teaware Appreciation and was favored by the students. The teaching of tea culture has achieved initial results in quality education. However, in the actual teaching process, there are still many problems that affect quality education. This paper analyzes the characteristics of humanistic quality education in colleges and universities and the status quo of Tea Culture and Ceramic Teaware Appreciation and proposes the current problems in the teaching of Tea Culture and Ceramic Teaware Appreciation, and tries to use teaching methods, teaching methods, assessment methods, etc. and make suggestions and countermeasures.
\end{abstract}

\section{Characteristics of Humanistic Quality Education in Colleges and Universities}

Conceptually, humanistic curriculum reflects the emphasis on sound personality, culture and abilities, rather than simply acquire knowledge. Educators generally agree that the purpose of education is to achieve the perfection of personality and not just the cultivation of certain people with professional skills. Therefore, the cultivation of the humanistic quality curriculum in colleges and universities places the cultivation of the ability and innovation of college students in an important position. From the content point of view, humanistic quality education is usually based on ancient and modern classics literature, history, philosophy, and art as the teaching focus. In teaching methods, humanistic quality education is usually based on independent reading and class discussion. Qualified humanistic quality education should be highly interactive between teachers and students and between students and students. The results of each lesson should also be open. There are no ready-made conclusions, and the process lies in the process.

\section{Problems in Tea Culture and Ceramic Teaware Appreciation course}

The curriculum is not "practical" and students are not very interested. China's tea culture is extensive and profound, and elective courses are very short. Therefore, how to enable learners to accurately comprehend and comprehend the essence of their thinking and spread their cultural connotations in a short period of time is the first key issue to be solved. At present, the main purpose of the curriculum of humanistic quality related to tea culture in colleges and universities is mainly through the teaching of tea culture and the appreciation of related teaware works, so that college students can feel the profoundness of Chinese tea culture and can comprehend and appreciate its ideological essence. Its content is more focused on tea history, tea politics, and tea law, which stays in the level of fixed history and events, lacking practical tea culture knowledge and skills that meet the needs of the times.

The Teaching Methods of tea Culture Courses Need to be Improved. Taking College of Technology and Art Jingdezhen Ceramic Institute for example, the current teaching of tea culture is 
similar to most courses in theory. There is less practical time for hands-on practice. Most students, after the courses, hardly have the chance to experience the process of tea and tea making. In addition, the lack of class discussion in teaching and the instillation of knowledge have greatly diminished the effect of disseminating humanistic traditions and values.

The Examination form is Simple, Students are Easy to Get Through. The professionalization of college education is still the mainstream today. Under the more direct guidance of this mainstream and the entire job market, to those who do not respect the university as an ivory tower, four years of college is more like a "warm-up match" before entering the workplace. Instead of spending time learning these "useless" courses, it is better to learn more professional skills and participate in social practice activities to get "real". Even worse, such courses often take the form of papers during exams. It is not hard to imagine that plagiarists abound. Most teachers do not have much time to verify the origin of each student's dissertation. At this time, for those students who have seriously read and wrote thesis, the most likely outcome is: Because the degree of "professional" papers they write is not as good as those of the plagiarists, they have worked hard to complete the course. The total score is not as good as those who only spent the time "copy and paste".

\section{Reflections on the Teaching of Humanistic Quality Course Tea Culture and Tea Set Appreciation in Colleges and Universities}

In the Selection and Refinement of Theoretical Knowledge, it is also Necessary to Combine the Exquisite Design theory with Practice in every Practical Teaching Process. Make full use of regional resources, such as Jingdezhen as a ceramic culture environment for the millennium porcelain city and the local domain resources of Fuliang County tea production area, and improve the three aspects of theory, inspection, and practice in designing teaching. If the funding permits, you can apply for a tea art classroom and arrange a tea art classroom to carry out practical training sessions so that students can initially master the kung fu process of the six major tea classes and understand the arrangement of tea mats and tea rooms. It is believed that the reform of this teaching method will be more able to attract students' interest in learning. It will help college students understand the spiritual connotation of tea art more directly and promote the cultivation of college students' aesthetic taste. In our college, students in the fine arts department have learned a great deal of theoretical basis and practical reference value through the study of tea culture and tea skills and the appreciation of ancient ceramic tea sets for the creation of ceramic art designs, especially ceramic tea sets.

College Education should Respect that Students' main Task is to Learn as the General Rule. Education must be people-oriented and teach students in accordance with their aptitude. It should focus on cultivating students' abilities of analysis, problem solving, and practical ability. In the setting of the humanistic quality education curriculum, the combination of classroom and extracurricular should be emphasized. The lecture method should focus on teaching and research. The humanistic quality courses set up should not only consider the promotion of students' cultural heritage, but also allow students to learn to think and evaluate independently. When teaching the contents of the tea set, the teaching method can be conducted in small classes or in groups. During the class, students and teachers can form a circle around the school desk where there is no such thing as a podium. This kind of discussion-based teaching method does not focus on imparting certain fixed knowledge to students. It is more about exploring the substantive content and value orientation of teaware works and expressing their opinions. Through the exploration, questioning, and refutation, excellent human traditions and values are spread. This is the fundamental purpose of setting up the humanistic quality curriculum. At the same time, the participants in the discussion must pay special attention to shelving their own judgmental opinions. In addition to expressing respect for the opinions of others, they can still retain room for amendments for their current views. People appreciate the classics of the humanistic and the arts together, not to reach a certain unified view when the discussion ends, but to experience the entire process of discussion together, and each of them gets richer and more diverse opinions than their original separate opinions. It can be imagined that in each discussion, each participant will be influenced by humanistic traditions and 
values that are rooted in the depths of human culture. This kind of spiritual nourishment is probably something that is hard to accept elsewhere.

Reform Assessment methods. Examination as an Important part of Teaching is an Important
Method to Test the Quality and Effectiveness of Teaching. At present, the assessment methods for elective humanistic courses in colleges and universities generally use assessment methods for submitting a dissertation or written examination. Although the assessment of the dissertation is conducive to the examination of students' ability of independent thinking and the level of language and writing, this test form is difficult to test the application ability of theory and practice; second, it is not easy to detect the breadth of students' theoretical knowledge; the third is in today's network information age, paper assessment can't bring students' academic motivation and pressure. Students usually put "Baidu" on the content they searched for, and some students even copy plagiarism on the Internet. The written test can check students' mastery of knowledge, but it is difficult to test students' practical ability and comprehensive qualities that they should have through study. For this reason, it is necessary for colleges and universities to reform the assessment methods of elective courses for the current humanistic qualities in order to improve the overall quality of college students. For the content and characteristics of elective courses in Tea Culture and Ceramic Teaware Appreciation, colleges and universities can choose a variety of flexible assessment methods, that is, student-centered, respecting students' individual differences and highlighting the focus of the curriculum. According to the actual situation of China's higher education, colleges and universities can take the combination of attendance rate + usual achievement + practical ability assessment. The attendance rate guarantees the student's participation in classroom learning; the usual grades focus on examining students' learning status, including completing assignments and periodic examinations; and practice-based assessment is the assessment of students' ability to use knowledge and overall quality. The following brief introduction to the Tea Culture and Ceramic Teaware Appreciation elective course assessment reform measures. The Tea Culture and Ceramic Teaware Appreciation course is a highly selective humanistic quality elective course. If the evaluation method can be combined with the subjective and practical operation forms, it is believed that those who are interested in reading, thinking and learning can use it easily and at least get high points. The final exam can take two forms: the class discussion score plus the recording group tea party video. The class discussion content can be prepared for the students one month in advance. In the class, comments and guidance on the opinions expressed by the students are given and scored. The practice session is to record the group tea party and display the results. This open form of assessment not only provides students with an excellent opportunity to show themselves and exercise themselves, but also can activate the classroom atmosphere and mobilize the students' enthusiasm for learning.

\section{References}

[1] Z.W.Cao, The Ideas and Practice of Humanistic Quality Education Courses in Colleges and Universities at Home and Abroad, Modern Business Industry 20(2013)

[2] S.Z.Xu, H.X.Wang, X.G.Li, Analysis of Public Elective Course Assessment Method,6,37, Agricultural Medical

[3] Peng L, Fang W. Heterogeneity of Inferring Reputation of Cooperative Behaviors for the Prisoners' Dilemma Game [J]. Physica A: Statistical Mechanics and its Applications, 2015, 433: 367-378. 